\title{
Accuracy of food photographs for quantifying food servings in a lunch meal setting among Danish children and adults
}

Biltoft-Jensen, Anja Pia; Nielsen, Trine Holmgaard; Ygil, Karin Hess; Christensen, Tue; Fagt, Sisse

Published in:

Journal of Human Nutrition and Dietetics

Link to article, DOI:

10.1111/jhn.12490

Publication date:

2018

Document Version

Peer reviewed version

Link back to DTU Orbit

Citation (APA):

Biltoft-Jensen, A. P., Nielsen, T. H., Ygil, K. H., Christensen, T., \& Fagt, S. (2018). Accuracy of food photographs for quantifying food servings in a lunch meal setting among Danish children and adults. Journal of Human Nutrition and Dietetics, 31(1), 131-140. https://doi.org/10.1111/jhn.12490

\section{General rights}

Copyright and moral rights for the publications made accessible in the public portal are retained by the authors and/or other copyright owners and it is a condition of accessing publications that users recognise and abide by the legal requirements associated with these rights.

- Users may download and print one copy of any publication from the public portal for the purpose of private study or research.

- You may not further distribute the material or use it for any profit-making activity or commercial gain

- You may freely distribute the URL identifying the publication in the public portal 
Accuracy of food photographs for estimating intake

\section{Accuracy of food photographs for quantifying food servings in a lunch meal setting among Danish children and adults.}

All from: The National Food Institute, Division for Risk Assessment and Nutrition, Technical University of Anja Biltoft-Jensen, Trine Holmgaard Nielsen, Karin Hess Ygil, Tue Christensen, Sisse Fagt. Denmark, Mørkhøj Bygade 19, 2860 Søborg, Denmark.

(1)

10

\section{Running head: Accuracy of food photographs for estimating intake} 5

Keywords: Portion size photos, food portion size, portion size estimations, dietary assessment, dietary surveys (1) 
Accuracy of food photographs for estimating intake

\section{Abstract}

Background: Visual aids, such as food photographs, are widely used in estimating food quantities in dietary surveys. The purpose of the present study was to assess how accurately Danish adults and children can estimate food portion sizes using 37 series of photographs illustrating 4-6 different portion sizes under real-life conditions, whether adults were more accurate than children, and to estimate the error caused by using portion-size photos to estimate weights of foods consumed in macronutrient calculation.

Methodology: 622 adults and 109 children were recruited in three workplace canteens and in two schools, respectively, to estimate their lunchtime portions based on photos. Participants were told to keep the foods separated on their plate when taking lunch. Participants thereafter estimated their own portions by looking at the relevant photo series. Then the actual food portions were weighed.

Results: The proportion of correct estimations was 42\% overall (range; 19\%-77\%). The mean difference (\%) between estimated and actual weight was 17\% (range; 1\%-111\%). Small portion size photographs were more often used correctly compared with larger portion photographs. Children had as many correct estimations as adults, but overestimated portions more. Participants using fractions of, or more than, one photo to estimate the portion of a food had significantly larger errors. When calculating the macronutrient content of a weekly menu using the estimated portion sizes, protein had the largest error (29\%).

Conclusion: When used in a real-life situation the portion size photos validated in the present study showed a certain inaccuracy compared with the actual weights. 


\section{Introduction:}

Quantification of consumed portions is associated with large measurement errors in most dietary assessment methods but food weighing (1).

In epidemiologic studies including dietary data collection and food surveillance and national dietary surveys, weighing of food portions is often not feasible. Standard portions, household-measures, food models and food photos have therefore been used as aids for quantitative estimation of the eaten food items (2-5). The use of standard portions assigns the same portions to all participants and thereby underestimates the true variation in eaten portion sizes and compromises the ability to rank participants according to true intake. The use of household measures to estimate intake may be particularly difficult for individuals who are not accustomed to using household measures in food preparation. Therefore, visual aids, such as photos of different portion sizes, have been widely used to improve participants' accuracy in reporting food quantities (6-9). Portion size photos are practical to distribute to participants in a dietary survey either in a booklet using paper or via the internet. Portion size photos are also used in the Danish National Survey of Diet and Physical Activity 201113 (DANSDA 2011-13) by participants to estimate portion size for a large number of foods (10).

Several authors have validated the accuracy of using portion size photos to estimate portion size (8,11-14). However, many studies have been conducted in controlled settings. In these studies, participants are invited to the investigating unit and are presented with a number of single preweighed foods on standard plates. Often the same foods weights and plates as presented on the food photographs are used as reference measures. Participants are asked to compare the portions presented on the plates to the portion sizes depicted in the photographs and to write down which photograph most closely corresponds to the portion on the plate $(8,11,12,15)$. This procedure has the advantage that the same participant can compare all of the different depicted food portions in a short time period. In the above-mentioned studies, between 15 to 52 servings were evaluated by the same participant in one setting. This sort of evaluation gives little information about the success of the use of portion size photos to estimate food portion sizes in a real dietary assessment. It tests participants' ability to compare a serving size of a single food to a photo of the exact same food. Foods eaten by individuals are often eaten as meals with several other food items on the plate, often overlapping and most likely appearing differently than the foods presented in the food photographs or in the pre-weighed foods participants were asked to compare with the photographs. In a real life situation, people serve themselves and eat what they give themselves, but in the studies, described 
participants are comparing foods and portion sizes that may not be relevant and familiar to participants, which may introduce errors. Furthermore, this “laboratory” validation technique does not allow for calculating how errors in portion size estimation by photos may influence the following nutrient calculation, because single food items are evaluated and not meals that allow for meaningful nutrient calculation.

The purpose of the present study was to assess how accurately Danish adults and children can estimate food portion sizes under realistic eating situation using photographs of foods, whether adults were more accurate than children, whether the option to specify fractions of a portion size image or to choose from two or more images to describe the portion were just as accurate as choosing the image that came closest to the portion size, and the influence of estimating portion sizes by photos or by weight on the calculation of macronutrient intake from a weekly lunch menu.

\section{Method}

\section{Food photographs}

The food photographs used in the present study were developed for use in the DANSDA 2011-13 among 4-75 year olds. The DANSDA 2011-13 uses a 7-day pre-coded food record where participants continuously record what they have eaten, and the portion sizes are given in predefined household measures (e.g. cups, glasses and spoons) or estimated from 41 series of photos of different portion sizes.

In the present study, 37 color portion size photo series were included. Each photo series included up to six photos of increasing and for fat spread decreasing portion sizes. The selection of food items for the food photographs was based on food items that both contribute significantly to energy and/or nutrient intake, and food items that would be difficult to estimate by household measures (as meat, fish, chicken cuts, vegetables, casseroles, filling on bread, rice, pasta, potatoes and other voluminous foods). The foods depicted in the photo series represented the most commonly eaten foods and dishes in Denmark.

As suggested by Nelson et al., the optimal number of photos in each series is between 4 and 8 , and $6(9 \times 6 \mathrm{~cm})$ were chosen as optimal for the DANSDA (16). For two of the photo series, fat spread on rye bread and fat spread on wheat bread, only four photos were chosen. Due to the small 
increment in grams between the small and large portion of fat spread, it would be difficult to see the difference among portions with more photos within the weight range. Nelson also recommends an equal number of photos in a photo series to avoid that participants always choose the middle photo (16). The two smallest portions represented on photos A and B were considered "Small”. The two middle size portions represented on photos C and D were considered “Medium”. The two largest portions represented on photos E and F were considered "Large”. For fat spread on bread with only four portion size photos, the smallest was considered “Small”, the two middle were considered "Medium" and the largest "Large".

The weights depicted on the photos were based on a survey investigating common food portion weights in Denmark among 258 children and adults (17). The weight intervals were equal increments between the $5^{\text {th }}$ and $95^{\text {th }}$ percentile, and slightly adjusted to represent a clear visual progression among photos. Furthermore, a suitable camera angle of 52 degrees for casseroles, meat, vegetables, potatoes/rice and pasta, and confectionary, 25 degrees for fat spread and filling on bread and 35 degrees for cake was applied to clearly demonstrate the volume of the foods (height and/or circumference), and based on a typical eating situation applying to the specific foods. Finally, the same size-relationship between the different photo-series was ensured. Most food photographs displayed the foods on a white plate measuring $27 / 22 \mathrm{~cm}$ (outer/inner diameter) which is the most commonly bought plate size in Denmark, including cutlery as a reference measure and using a light grey color as background. Chicken pieces and fat spread were displayed on a large cutting board containing all portion sizes, with one image size of 16 x $19 \mathrm{~cm}$. Candy and chocolate were displayed directly on the background.

\section{Subjects}

622 adults (19-68 years) and 109 children (8-12 years) participated in the validation study. The adults were recruited from three companies and the children through recruiting whole school classes from two different schools in the Copenhagen area. In one of the schools, the children brought packed lunches from home while the other had a school lunch buffet programme. All of children in school on the days of measuring participated in the study. All the companies had canteens with lunch buffets. Two of the companies employed office workers and one was a defense college. The heads of the companies and schools were approached by telephone followed by written information material. After approval, contact was made with the canteen leaders or teachers for further arrangements. 


\section{Design}

In all companies and schools, the relevant lunch portion sizes were estimated using the portion size photos and weighed over 3-5 days. The menu plans were given to the research team beforehand, so it was possible to plan the testing of the different photo series. It was the intention to get $\geq 50$ observations for each photo series. This goal was used to guide the number of days spent at each company canteen and to negotiate with the canteen leader about the menus. Occasionally cakes and sweets were on the lunch buffets and in the children's lunch boxes. These items were included in the photos, weighed and estimated in the same way as other foods.

Adult participants were recruited in the company canteen directly by the research team before or while standing in lunch queue. Participants were instructed to separate foods on the plate (e.g. gravy on the side, butter on the side, etc.). After participants had taken their food, photos were taken of the plates using a Nikon COOLPIX S700 digital camera (12.1-Megapixel) and a cubelite (Lastolite Cubelite $58 \mathrm{~cm}$ ). These photos were used as documentation. Thereafter, participants estimated their own portions by looking at the relevant photo series. Participants were asked to determine which photo in the series corresponded best to the portion on their plate. They were allowed to choose fractions of a photo portion or more than one photo within a photo series to describe the served portion size of one food, e.g. a small portion could be $1 / 2$ B rather than one portion A. Afterwards, the different types of food on the plate were weighed (Soehnle; Vera 67002, with a precision of \pm 1 g) by carefully transferring the food, item-by-item, to another plate standing on the scale Finally, the participants were asked to state their age and education (adults) before eating their meal.

In the school where the children brought packed lunch from home, the classes received a short instruction in the classroom. Solid white polystyrene plates (Model LINPAC; Size $26 \mathrm{~cm}$ ) marked with class, date, ID numbers were distributed to all children in the classroom, and the children were asked to unpack their lunch and place the different meal elements separately on the plate. All children went through the same procedure as the adults with photographing, portion size estimation using photos, and weighing their lunch. In the school with the lunch buffet, the same procedure was conducted.

This study was conducted according to the guidelines laid down in the Declaration of Helsinki. Information to the parents was sent through the schools electronic communication system, and informed consent was provided to the teacher using this system. 


\section{Data analysis}

The agreement between the photograph chosen by the participants and the actual weight of the food portions was calculated and illustrated in several ways:

- As a percentage of estimations choosing the correct photo, the photo adjacent to the correct photo or a distant photo when comparing food portions on the plate to portion size photos. If actual weight was within half of the increment between photo weights (on both sides of photo weights) in a photo series it was considered a correct estimation.

- As an error in relation to actual weight: photo weight (g) - actual weight (g), and as mean percent: mean photo weight (g) - mean actual weight (g)/mean actual weight (g) x100. Negative error/error rates indicate underestimation and a positive error/error rate indicates overestimation.

- Wilcoxon's test was used to test for the differences between the photo and actual weights.

- Spearman correlations between the estimated portion (by photo) and the actual portion (by weight) within a photo series were used to test the correlation between the portion sizes chosen and the actual weights.

- Mann-Whitney test was used to test if using a fraction of, or more than, one photo to estimate portion size gave different errors than when using one photo for the estimation, and to test the difference between children and adults.

- $\mathrm{Chi}^{2}$ was used to test if the percent correct estimations and direction of errors were the same when using the small, medium and large portion size photos for the estimation.

The statistical analysis was carried out with the SPSS statistical package (SPSS, version 23, 2015).

Finally, to estimate the magnitude of error introduced in the nutrition calculation when using photo weights, the macronutrient intake was calculated for a weekly lunch menu estimated by portion size photos and the actual weights. The weekly menu was composed from all the different workplaces and schools and was constructed to include most of the portion size photos (95\%). Only food items with a corresponding portion size photo were estimated and weighed. Since there was no portion size photos for bread, bread was not weighed. Bread is therefore not included in the nutrition calculation. Nutrient calculations were performed using the General Intake Estimation System (Version 1.000i6) developed at the National Food Institute, Technical University of Denmark, and the Danish Food Composition Databank (version 7, Søborg, Denmark, 2009). 
Accuracy of food photographs for estimating intake

194

195

196

197

198

199

200

201

202

203

204

205

206

207

\section{Results}

\section{Characteristics of participants}

The characteristics of participants are shown in Table 1. The presented characteristics are weighted according to the number of portion size estimations done by each participant since this differed from participant to participant. The mean (range) number of portion estimations from each participant was 3 (1-9). The mean (SD) age of adults was 40 (12) years and of children 9 (1) years. Males/boys did a little more than half of the portion size estimations. Among the adults, two-thirds of the portion size estimations were done by those having a medium level or long education.

\section{Precision of portion size estimations}

The mean of percent correct estimations in all categories was 42\% (Table 2); 17\% of the food, portions were estimated smaller than the actual portion and $41 \%$ were estimated larger. The proportion of correct estimations was below $50 \%$ for $70 \%$ of the photo series. The proportion of correct estimations was lowest for mayonnaise-based salads (11\%) and highest for rice (77\%) and tomato slices (73\%) (Results not shown).

Correlation coefficients between the estimated portions and actual portions ranged between 0.18 (meat sauce) and 0.89 (chocolate). Three photo series (mayonnaise-based salads, fish fillet, and meat sauce) had non-significant correlations (results not shown). The mean estimation error percentages for all food servings were 17\% (Table 2) ranging from -1\% (liver paste) to 111\% (cooked/baked potatoes) (results not shown). Only for vegetables were there no significant differences between photo weight and actual weight.

The positive direction of the errors for most photo series indicates a trend to estimate servings larger than the actual weight. Filling on bread, vegetables and pasta were more likely to be underreported than the rest of the photo series.

In the present study, $12 \%$ of the participants chose to use a fraction of one photo or two photos within the same photo series to describe their portion size. The results showed that using a fraction of one photo or two photos compared with one photo gave significantly larger estimation errors $(\mathrm{P}=0.006)$ (Table 3).

The results presented in Table 4 show that portions estimated by the small portion size photos were more likely to be correct than portions estimated by medium and large portion size photos (Percent 
Accuracy of food photographs for estimating intake

error: small -4 vs. medium/large 22/23). When using the large portion size photos, $59 \%$ of the estimations resulted in overestimation.

Figure 1 illustrates the ability of adults to choose the correct photo compared with the ability of children. The result shows that children, in just as many cases as adults, choose the correct photo. However, when children are making estimation errors, they are more likely to be positive compared with adults who have larger negative estimation errors compared with children. This also results in a significant larger positive estimation error in grams and percentages in children (21.4 g; SE: 1.2; 40\%) than for adults (12.2 g; SE: 2.3; 15\%) (P<.001) (Results not shown).

The influence of using estimated weight vs. actual weight on macronutrient calculation for a weekly lunch menu showed overall error estimation percentage (min-max) of 21\% (5\% - 38\%) for energy, $29 \%$ (8\%-44\%) for protein, 21\% (4\%-33\%) for total fat, $26 \%$ (15\%-42\%) for saturated fat, $16 \%$ (4\%-35\%) for carbohydrate, 20\% (8\%-36\%) for added sugar and 9\% (-17\%-19\%) for dietary fiber depending on the menu type. The macronutrient content based on the children's lunch showed much larger overestimations than for adults (Table 5).

\section{Discussion}

In the present study, portion size photos were validated in a real-life setting for both adults and children. Furthermore, the macronutrient content was calculated and compared when using portion size photos to estimate intake and using the actual weight of foods. This study showed that overall only $42 \%$ of the study population was able to pick the correct photo, and that this was not different for children (Adults: 44\% vs. children: 41\%). However, children's mean estimation error was larger because they tended to overestimate more than adults did. In other studies, it was also found that when using age-appropriate portion size photos, children (4-11 years) were just as accurate as adults $(8,13)$. The study of Foster et al. (2006) also found that children were more likely to overestimate the portion size of foods and dishes compared with adults (13).

The use of the photos illustrating the larger portion sizes lead to larger positive estimation errors in grams and percentages. This was also seen in a Finnish study with adults validating food servings against portion size photos (12). This could be because of the difficulties in noticing the difference between large portions if the increment size is relatively small. Most studies have used an equal 
increment between portions from the $5^{\text {th }}$ and $95^{\text {th }}$ percentile based on data from national dietary surveys $(6,14,18-21)$. In some studies, they made increments on a log scale between the portion sizes to overcome the difficulties distinguishing between larger portions $(11,18)$. Using a log scale might also lead to greater errors when choosing large portions because of greater portion differences. In the present study, equal increments were chosen, but small adjustments were made to ensure visual increment difference between photos.

The errors related to the choice of large portion photos could also be due to the perception of size and depth of the two dimensional portion size photos, and the photo angle used when taking the photos. Food portions taken from an angle, as in the present study, seem smaller than photos taken from above as the angle visually shrinks the plate, and it becomes more oval in shape. However, Subar et al. (2010) studied the importance of the angle of the pictures taken from above and with an angle of 45 degrees for 27 portion size images of foods (21). The only food where there was significant difference between estimation errors at the two angles was for potato chips, which were determined best by photos obtained at 45 degrees. The study also illustrated that participants preferred the photos taken from above, but the preference is not reflected in smaller estimation errors. Few other studies have used photos taken from above. Thoradeniya et al. (2012) was the only study that exclusively used photos that were taken from above (19).

The present study also illustrated that using fractions of, or more than, one photo portion to estimate the portion size of the food served introduced larger errors than choosing the photo closest to the portion size served. This has, to the authors' knowledge, not been reported before in the scientific literature. Nelson et al. (1994) showed that a series of eight photos provided more accurate estimates than just one photo where the participants should indicate the percentage or fraction of the displayed portion corresponding to the served portion (6). In other studies, participants had the opportunity to indicate that the portion was "smaller than the smallest portion" or "larger than the largest portion" in a photo series, but the results were not reported according to use of these options $(14,22)$.

Finally, we estimated the size of error on the estimated intake of macronutrients from a weekly lunch menu using the portion size photos compared with the real weight. This showed total estimation error percentages from $9 \%$ for dietary fiber to $29 \%$ for protein. Energy was overestimated by $21 \%$, so it is likely that other macronutrients were overestimated to the same degree. This was not the case for carbohydrates and dietary fiber. However, bread was not included 
in the calculations, and pasta and rice had fairly high percentages of correct estimations ( $57 \%$ and 77\%, respectively). On the other hand, meat and casserole portions were frequently overestimated, and overall meat portions were overestimated by $51 \%$ and casserole portions by $55 \%$. This can explain the larger difference in protein (29\%) and saturated fat (26\%) between estimated and actual food portions.

Several of the photo series in the present study (casseroles, meat and fish, rice and pasta, vegetables, cake) were also included in another validation study, only moderated slightly to reflect the portion sizes for children 3-10 years (11), but using the same plates, the same foods, the same angels, photographer etc. These photo series were validated in a "laboratory" condition where parents of 310 year olds evaluated predefined servings of single foods across three European countries. For most of the photos, but not all, there were more correct estimations. This could be due to the validation method where the vast majority of the predefined servings validated were exactly similar foods as the ones on the portion size photos. This might not represent a realistic use of the portion size photos in, e.g., a national dietary survey. Therefore, the validation method may also produce a better result than can be expected in real life.

Turconi et al. (2005) also validated 434 portion size photo series, with each series illustrating three portions among 448 volunteers in a real-life setting, similar to the present study. They, however, reported the errors of the 9075 assessments in five broad food groups, and because of the large number of observations, the mean differences were small (3\%-11\%) (7). In the present study, there were 2202 observations, and the overall difference in percent was 17\%, and the mean difference in the 7 food groups ranged from $-7 \%$ to $44 \%$.

Subar et al. (2010) also mimicked real-life in their validation of digital portion size photos. They found that $14 \%$ of all the foods they included were estimated within $\pm 10 \%$ of the actual weight, in the present study it was 18\%. The study of Subar et al. (2010) also found that drawings of generic mounds or household measures (cups, glasses, bowls) were as accurate as photos of food portions and therefore are cost-effective alternatives to photos of foods (14). In the study of Frobisher and Maxwell (2003), it was also found that standard descriptions of portion sizes performed no worse or better than photographs of portion sizes (23). In an Irish study by Faulkner et al. (2016), they evaluated the precision and ease of use of different portion size estimation aids and they found that food photos were the least precise and that household measures (portion pots and cups) were easy to 
use and relatively precise. However, the study focused on an aid's ability to help participants to choose an appropriate serving size (24).

Even if participants choose the correct photo, the mean difference between actual weight and photo weight can be relatively high if the weight span within a photo series is large. If in a wide weight span only a few photo portions are available to choose among, a high percentage of correctly estimated portion sizes is more likely, but because the weight distance between the photos is large, there could be large differences between estimated and actual weight.

Small portions of foods such as cold cuts of meat and fat spread get high error percentages very easily for a small overestimation of e.g. $2 \mathrm{~g}$, because all photos show small amounts with small weight increments between. Several studies have showed large overestimations of fat spread on bread $(8,25,26)$. The major estimation error of fat can be problematic for the calculation of fat and energy intake. Therefore, having an optimal number of photos and an appropriate weight range for the target group is important. Studies suggest that photo series with more photos provide higher accuracy than photo series with fewer photos (eight vs. four; five vs. three; eight vs. one photo). But in these studies, photo series with fewer photos seemed to be easier for participants to grasp $(6,12,14,19,27)$.

The strength of the present study is that it was conducted in a real-life setting closer to the use of the food portion photographs in the DANSDA where the food intake is to be recorded on a continuous basis. The validation technique used also allowed for performing nutrient calculation on a weekly menu to get an idea of the error size introduced in macronutrient calculations when using the photo weights compared with the actual weight. A weakness was that participants estimated their portions before eating and not after eating as would probably be the procedure in a dietary assessment/survey. In the present study, participants did not have to take memory and waste into account, which could have introduced even larger errors. Therefore, the present study qualifies as a perception study according to the psychological constructs involved in portion size estimation using food photographs proposed by Nelson \& Darbyshire in 1994 (6). Furthermore, participants were asked to separate the food on the plate when taking a portion. Serving, e.g., the meat sauce on top of the rice would have made estimations more difficult. 
Accuracy of food photographs for estimating intake

\section{Conclusion}

Photos of different food portion sizes are cost-effective compared with actual weights as a portion estimation tool and widely used in dietary surveys. However, the photos validated in the present study were not very accurate when used in a realistic situation compared to actual weights. This has substantial influence on estimated food intake and nutrient calculations.

\section{Acknowledgement}

The authors would like to thank the caterers, children and adults in the participating schools and companies for taking part in this study and for helping with the planning of relevant menus, estimating their portion sizes using photos and letting us weigh their lunch meals in portions of food. The study was internally funded. The authors declare no conflict of interest.

\section{Transparency Declaration}

The lead author affirms that this manuscript is an honest, accurate, and transparent account of the study being reported, that no important aspects of the study have been omitted and that any discrepancies from the study as planned (and registered with) have been explained. The reporting of this work is compliant with STROBE guidelines. The lead author affirms that no important aspects of the study have been omitted and that any discrepancies from the study as planned have been explained. The study has not been registered in any trials registry.

\section{Author contributions:}

The authors' contributions are as follows: APBJ, KHYG, TRHNI, SFA, TUCHR designed the study and formulated the research questions; ABJ, TRHNI and KHYG collected the dietary intake data. APBJ drafted the manuscript. All authors took part in a critical revision of the manuscript and approved the final version of the paper. 
1. Gibson RS. Principles of Nutritional Assessment. Second ed. Oxford: Oxford University Press; 2005.

2. Young LR, Nestle MS. Portion sizes in dietary assessment: issues and policy implications. Nutr Rev. 1995;53:149-58.

3. Haraldsdottir J, Tjonneland A \& Overvad K. Validity of individual portion size estimates in a food frequency questionnaire. Int J Epidemiol. 1994;23:786-96.

4. Cypel YS, Guenther PM \& Petot GJ. Validity of portion-size measurement aids: a review. J Am Diet Assoc. 1997;97:289-92.

5. Godwin SL, Chambers E \& Cleveland L. Accuracy of reporting dietary intake using various portion-size aids in-person and via telephone. J Am Diet Assoc. 2004;104:585-94.

6. Nelson M, Atkinson M \& Darbyshire S. Food photography: The perception of food portion size from photographs. Br J Nutr. 1994;72:649-63.

7. Turconi G, Guarcello M, Berzolari FG, et al. An evaluation of a colour food photography atlas as a tool for quantifying food portion size in epidemiological dietary surveys. Eur J Clin Nutr. 2005;59:923-31.

8. Lillegaard IT, Overby NC \& Andersen LF. Can children and adolescents use photographs of food to estimate portion sizes? Eur J Clin Nutr. 2005;59:611-17.

9. Smith K, Sampson G, Probst Y, et al. Development of Australian portion size photographs to enhance selfadministered online dietary assessments for adults. Nutr Diet. 2010;4: 275-80.

10. Biltoft-Jensen A, Matthiessen J, Rasmussen LB, et al. Validation of the Danish 7-day precoded food diary among adults: energy intake v. energy expenditure and recording length. $\mathrm{Br}$ J Nutr. 2009;102:1838-46.

11. Trolle E, Vandevijvere S, Ruprich J, et al. Validation of a food quantification picture book targeting children of $0-10$ years of age for pan-European and national dietary surveys. $\mathrm{Br} \mathrm{J}$ Nutr. 2013;110:2298-308.

12. Ovaskainen ML, Paturi M, Reinivuo H, et al. Accuracy in the estimation of food servings against the portions in food photographs. Eur J Clin Nutr. 2008;62:674-81.

13. Foster E, Matthews JN, Nelson M, et al. Accuracy of estimates of food portion size using food photographs--the importance of using age-appropriate tools. Public Health Nutr. 2006;9:50914. 14. Subar AF, Crafts J, Zimmerman TP, et al. Assessment of the accuracy of portion size reports using computer-based food photographs aids in the development of an automated self-administered 24-hour recall. J Am Diet Assoc. 2010;110:55-64. 
15. Foster E, Adamson AJ, Anderson AS, et al. Estimation of portion size in children's dietary assessment: lessons learnt. European Journal of Clinical Nutrition. 2009;63:S45-S49.

16. Nelson M, Haraldsdottir J. Food photographs: practical guidelines II. Development and use of photographic atlases for assessing food portion size. Public Health Nutr. 1998;1:231-37.

17. Nielsen TH, Biltoft-Jensen A, Ygil KH et al. (2011) Undersøgelse af portionsstørrelser blandt danskere i alderen 4 til 75 år (Investigation of food portion sizes among 4-75 year old Danes). DTU Fødevareinstituttet, Danmarks Tekniske Universitet.

18. Foster E, Matthews JN, Lloyd J, et al. Children's estimates of food portion size: the development and evaluation of three portion size assessment tools for use with children. $\mathrm{Br} \mathrm{J}$ Nutr. 2008;99:175-84.

19. Thoradeniya T, de SA, Arambepola C, et al. Portion size estimation aids for Asian foods. J Hum Nutr Diet. 2012;25:497-504.

20. Slimani N, Deharveng G, Charrondiere RU, et al. Structure of the standardized computerized 24-h diet recall interview used as reference method in the 22 centers participating in the EPIC project. European Prospective Investigation into Cancer and Nutrition. Comput Methods Programs Biomed. 1999;58:251-66.

21. Toobert DJ, Strycker LA, Hampson SE, et al. Computerized portion-size estimation compared to multiple 24-hour dietary recalls for measurement of fat, fruit, and vegetable intake in overweight adults. J Am Diet Assoc. 2011;111:1578-83.

22. Lucas F, Niravong M, Villeminot $S$, et al. Estimation of food portion size using photographs: validity, strengths, weaknesses and recommendations. J Hum Nutr Diet. 1995;8:65-74.

23. Frobisher C, Maxwell SM. The estimation of food portion sizes: a comparison between using descriptions of portion sizes and a photographic food atlas by children and adults. J Hum Nutr and Diet. 2003;16:181-8.

24. Faulkner GP, Livingstone MB, Pourshahidi LK, et al. An evaluation of portion size estimation aids: precision, ease of use and likelihood of future use. Public Health Nutr. 2016;19:2377-87.

25. Nelson M, Atkinson M \& Darbyshire S. Food photography II: use of food photographs for estimating portion size and the nutrient content of meals. Br J Nutr. 1996;76:31-49.

26. De Keyzer W, Huybrechts I, De Maeyer M, et al. Food photographs in nutritional surveillance: errors in portion size estimation using drawings of bread and photographs of margarine and beverages consumption. Br J Nutr. 2011;105:1073-83.

27. Robson PJ, Livingstone MB. An evaluation of food photographs as a tool for quantifying food and nutrient intakes. Public Health Nutr. 2000;3:183-92. 
438 Table 1. Characteristics of children and adults who took part in the study.

\begin{tabular}{|l|c|c|}
\hline Characteristics* $^{*}$ & $\begin{array}{c}\text { Adults } \\
(\mathbf{n}=\mathbf{6 2 2}, \mathbf{1 8 4 0} \text { estimations) }\end{array}$ & $\begin{array}{c}\text { Children } \\
\text { (n=109, 362 estimations) }\end{array}$ \\
\hline Age, mean (sd) & $40(12)$ & 9 (1) \\
\hline Males (\%) & 59 & 53 \\
\hline Education (\%) & & - \\
\hline $\begin{array}{l}\text { No/vocational/short (below 13 } \\
\text { years) }\end{array}$ & 33 & - \\
\hline Medium/long (13 years or above) & 64 & \\
\hline Missing & 3 & \\
\hline
\end{tabular}

$439 *$ Numbers are weighed by number of estimations 
Table 2. Percentages of participants choosing the correct, adjacent or distant photo when comparing photo weight to actual weight. Difference and standard error (SE) of the difference between the photo weight and actual weight in grams. The mean difference as a percentage of the actual weight. Spearman correlation between the photo weight and the actual weight.

\begin{tabular}{|c|c|c|c|c|c|c|c|c|c|c|c|c|}
\hline \multirow[t]{2}{*}{ Food items } & \multirow[t]{2}{*}{$\begin{array}{l}\text { Photo } \\
\text { series }\end{array}$} & \multirow[t]{2}{*}{$\begin{array}{l}\text { Obser- } \\
\text { vations } \\
\mathbf{N}\end{array}$} & \multirow{2}{*}{$\begin{array}{l}\text { Corre } \\
\text { ct } \\
\text { photo" } \\
(\%)\end{array}$} & \multicolumn{2}{|c|}{$\begin{array}{c}\text { Adjacent } \\
\text { photo } \\
\text { (\%) }\end{array}$} & \multicolumn{2}{|c|}{$\begin{array}{c}\text { Distant } \\
\text { photo (\%) }\end{array}$} & \multirow{2}{*}{$\begin{array}{c}\text { Mean } \\
\text { photo } \\
\text { weight } \\
\text { g } \pm\left(\mathrm{SE}^{\mathrm{f}}\right)\end{array}$} & \multirow{2}{*}{$\begin{array}{c}\text { Mean } \\
\text { actual } \\
\text { weight } \\
\mathrm{g} \pm\left(\mathrm{SE}^{\llbracket}\right)\end{array}$} & \multirow{2}{*}{$\begin{array}{c}\text { Mean } \\
\text { difference: } \\
\text { Photo weight - } \\
\text { actual weight } \\
\text { g } \pm\left(\mathrm{SE}^{\mathrm{I}}\right)^{\mathrm{I}} \\
\end{array}$} & \multirow[t]{2}{*}{$\begin{array}{c}\text { Mean } \\
\text { difference } \\
\%\end{array}$} & \multirow[t]{2}{*}{$\begin{array}{l}\text { Spearmanc } \\
\text { orrela-tion }\end{array}$} \\
\hline & & & & -1 & +1 & $\begin{array}{r}>- \\
1\end{array}$ & $>+1$ & & & & & \\
\hline Fat spread on bread & 2 & 121 & 28 & 13 & 31 & 2 & 26 & $10.7(0.6)$ & $8.8(0.5)$ & $1.9(0.4)^{* *}$ & 22 & $0.69 * *$ \\
\hline Filling on bread & 7 & 370 & 35 & 15 & 20 & 11 & 19 & $41.3(1.5)$ & $38.2(1.3)$ & $3.1(1.4)^{*}$ & 8 & $0.67 * *$ \\
\hline Meat/fish & 7 & 403 & 33 & 7 & 33 & 1 & 26 & $115.3(3.1)$ & $80.0(1.8)$ & $35.3(2.4)^{* *}$ & 44 & $0.69 * *$ \\
\hline Casseroles & 3 & 105 & 30 & 8 & 42 & 3 & 17 & $200.7(7.0)$ & $146.0(6.1)$ & $55.2(7.4)^{* *}$ & 38 & $0.37 * *$ \\
\hline Potatoes/rice/pasta & 5 & 363 & 54 & 11 & 23 & 2 & 10 & $127.8(4.3)$ & $109.3(3.4)$ & $18.5(3.7)^{* *}$ & 17 & $0.69 * *$ \\
\hline Vegetables & 9 & 571 & 49 & 16 & 19 & 11 & 5 & $79.1(2.6)$ & $85.2(3.3)$ & $-6.1(1.9)$ & -7 & $0.76^{* *}$ \\
\hline $\begin{array}{l}\text { Cake and } \\
\text { confectionary }\end{array}$ & 4 & 269 & 45 & 6 & 36 & 1 & 12 & 105.1 (3.5) & $84.4(3.0)$ & $20.6(2.0)^{* *}$ & 24 & $0.83 * *$ \\
\hline Total & 37 & 2202 & 42 & 11 & 26 & 6 & 15 & $92.6(1.6)$ & 78.9 (1.4) & $13.7(1.1)^{* *}$ & 17 & $0.83 * *$ \\
\hline
\end{tabular}

$*=<0.05 ; * *<0.001$

${ }^{\S}$ Spearman correlation between estimated portion (by photo) size and actual portion size (by weight).

"As the number of estimations for each photo series was different, the standard error was chosen as a measure of the precision of the sample mean since the standard error depends on both the standard deviation and the sample size.

Ł To test whether the estimation method significantly overestimated or underestimated, the consumed portion was tested with Wilcoxon’s Signed Rank test.

"If actual weight was within half of the increment between photo weights (on both sides of photo weights) in a photo series it was considered a correct estimation. 
Accuracy of food photographs for estimating intake

Table 3. Mean difference percentage when using one or fractions of or more than one photo for estimating portion size.

\begin{tabular}{|l|l|l|l|}
\hline $\begin{array}{l}\text { Number of } \\
\text { photos used to } \\
\text { assess portion } \\
\text { size }\end{array}$ & $\begin{array}{l}\text { One photo } \\
(\mathbf{n = 1 9 2 8 )}\end{array}$ & $\begin{array}{l}\text { Fractions of or } \\
\text { more than one } \\
\text { photo (n=274) }\end{array}$ & P-value* \\
\hline $\begin{array}{l}\text { Mean difference } \\
\mathrm{g} \pm \text { SE (\%) }\end{array}$ & $\begin{array}{l}12 \pm 1.0 \\
(15)\end{array}$ & $\begin{array}{l}29 \pm 4.8 \\
(40)\end{array}$ & \\
\hline $\begin{array}{l}\text { Median } \\
\text { difference g, } \\
\text { P25;P75 (\%) }\end{array}$ & $\begin{array}{l}0(0 ; 35) \\
(0)\end{array}$ & $\begin{array}{l}10(-3 ; 38) \\
(18)\end{array}$ & .006 \\
\hline
\end{tabular}

*Mann Whitney test 
Table 4. Percent correct estimations and direction of errors and error size in g and percent when using the small, medium and large portion size photos.

\begin{tabular}{|c|c|c|c|c|c|c|c|}
\hline $\begin{array}{c}\text { Portion } \\
\text { size } \\
\text { photos }^{\S}\end{array}$ & $\begin{array}{c}\text { Photo } \\
\text { portion }^{\text {letter }}\end{array}$ & $\begin{array}{c}\text { Number of } \\
\text { observations }\end{array}$ & $\begin{array}{c}\text { Correct } \\
\text { estimation } \\
\mathbf{( \% )}\end{array}$ & $\begin{array}{c}\text { Smaller } \\
\text { estimation } \\
\mathbf{( \% )}\end{array}$ & $\begin{array}{c}\text { Larger } \\
\text { estimation } \\
\mathbf{( \% )}\end{array}$ & $\begin{array}{c}\text { Mean } \\
\text { difference: } \\
\text { Photo } \\
\text { weight - } \\
\text { actual } \\
\text { weight } \\
\text { g } \pm \text { (SE) }\end{array}$ & $\begin{array}{c}\text { Mean } \\
\text { difference } \\
\text { \% }\end{array}$ \\
\hline Small & A, B & 774 & 65 & 20 & 15 & $-2.6(1.0)$ & -4 \\
\hline Medium & C, D & 809 & 30 & 14 & 56 & $19.2(1.6)$ & 22 \\
\hline Large & E, F & 345 & 22 & 19 & 59 & $25.7(3.2)$ & 23 \\
\hline All & & $1928 *$ & 43 & 17 & 40 & $12.6(1)$ & 15 \\
\hline
\end{tabular}

Distributions of correct-, under- and overestimation are significantly different between small, medium and large portion size photos P-value $<0.001$. Analyzed by chi2 test

*Only those estimations which included portion size estimation by one photo

$\S$. The two smallest portions represented on photos A and B were considered "Small”. The two middle size portions represented on photos C and D were considered "Medium". The two largest portions represented on photos E and Fwere considered "Large". For fat spread on bread with only four portion size photos, the smallest was considered "Small", the two middle were considered "Medium" and the largest "Large". 
Table 5: Mean dailymacronutrient content for a weekly lunch menu estimated by photo weight and actual weights. Mean differences in kilojoule and grams and in percent.

\begin{tabular}{|c|c|c|c|c|c|c|}
\hline $\begin{array}{l}\text { Lunch menu } \\
\text { including occasional } \\
\text { cakes and sweets for } \\
\text { one week (mean } \\
\text { estimated vs. mean } \\
\text { weighed grams) }\end{array}$ & Macronutrients & $\begin{array}{l}\text { Photo } \\
\text { weight } \\
\text { (mean) }\end{array}$ & $\begin{array}{l}\text { Actual } \\
\text { weight } \\
\text { (mean) }\end{array}$ & $\begin{array}{l}\text { Difference: } \\
\text { Photo } \\
\text { weight - } \\
\text { actual } \\
\text { weight } \\
\text { (mean) }\end{array}$ & $\begin{array}{l}\text { Difference } \\
\text { in percent } \\
\text { (mean) }\end{array}$ & $\begin{array}{l}\text { Min- } \\
\text { max } \\
\%\end{array}$ \\
\hline \multicolumn{7}{|l|}{ Children, $n=109$} \\
\hline & Energi $(\mathrm{Kj})$ & 2486 & 1652 & 833 & 50 & $28-66$ \\
\hline & Protein (g) & 29,4 & 19,4 & 9,9 & 51 & $27-79$ \\
\hline & Total fat (g) & 32,8 & 19,9 & 12,9 & 65 & $49-77$ \\
\hline & Saturated fat (g) & 12,2 & 7,4 & 4,8 & 66 & $50-80$ \\
\hline & Carbohydrate (g) & 47,3 & 35,9 & 11,5 & 32 & $1-65$ \\
\hline & Sugar $(\mathrm{g})$ & 10,5 & 6,3 & 4,2 & 66 & $50-133$ \\
\hline & Dietary fiber (g) & 3,6 & 2,7 & 1,0 & 38 & $18-65$ \\
\hline \multicolumn{7}{|l|}{ Adults, $n=622$} \\
\hline & Energi (Kj) & 3636 & 3091 & 544 & 18 & $1-40$ \\
\hline & Protein $(\mathrm{g})$ & 42,8 & 34,1 & 8,7 & 26 & $1-45$ \\
\hline & Total fat $(\mathrm{g})$ & 47,1 & 40,2 & 7,0 & 17 & $3-38$ \\
\hline & Saturated fat (g) & 19,0 & 15,6 & 3,4 & 22 & $4-43$ \\
\hline & Carbohydrate (g) & 71,2 & 62,9 & 8,3 & 13 & $-3-29$ \\
\hline & Sugar (g) & 25,7 & 21,9 & 3,8 & 17 & $8-32$ \\
\hline & Dietary fiber (g) & 5,2 & 4,8 & 0,4 & 8 & $-19-15$ \\
\hline \multicolumn{7}{|l|}{ All, $n=731$} \\
\hline & Energy $(\mathrm{KJ})$ & 3448 & 2855 & 593 & 21 & $5-38$ \\
\hline & Protein (g) & 41,2 & 31,9 & 9,3 & 29 & $8-44$ \\
\hline & Total fat (g) & 44,0 & 36,4 & 7,6 & 21 & 4-33 \\
\hline & Saturated fat (g) & 17,8 & 14,1 & 3,7 & 26 & $15-42$ \\
\hline & $\begin{array}{l}\text { Carbohydrates } \\
\text { (g) }\end{array}$ & 68,6 & 59,2 & 9,4 & 16 & $4-35$ \\
\hline & Sugar (g) & 24,1 & 20,1 & 4 & 20 & $8-36$ \\
\hline & Dietary fiber (g) & 4,8 & 4,4 & 0,4 & 9 & $\begin{array}{r}-17-- \\
19\end{array}$ \\
\hline
\end{tabular}

